\title{
UM ESTUDO SOBRE SABERES TRANSVERSAIS PARA REFLEXÃO NA EDUCAÇÃO PROFISSIONAL E TECNOLÓGICA
}

\author{
A study on transversal knowledge for a reflection \\ on vocational and technological education
}

\section{Un estudio sobre el conocimiento transversal para la reflexión en la educación profesional y tecnológica}

RESUMo Este trabalho exibe um estudo sobre saberes transversais à luz de considerações teóricas, quanto aos conceitos de multidisciplinaridade, interdisciplinaridade e transdisciplinaridade. Tem-se como objetivos discutir os saberes transversais e apresentar exemplos e esquemas representativos a respeito dessas noções em torno do conhecimento disciplinar. A metodologia, de abordagem qualitativa, fundamenta-se em conceitos teórico-metodológicos acerca de interdisciplinaridade e transdisciplinaridade, além de se considerar a complexidade e o paradigma rizomático deleuziano. Propõe-se, assim, uma reflexão sobre o currículo na Educação Profissional e Tecnológica (EPT), mais especificamente considerando a construção de saberes pertinentes à educação tecnológica de nível superior. Essa discussão, dos saberes disciplinares aos saberes transversais, mostra-se relevante na educação profissional e tecnológica, frente aos desafios que se impõem no atual contexto, diante da necessidade por inovação, visando-se a uma formação mais abrangente, em que se considere a multiplicidade dos saberes.

PalaVRas-Chave: Educação Profissional E TECNOLÓGICA. FormaÇÃO INTEGRAL. CURRÍCULO. INTERDISCIPLINARIDADE. TRANSDISCIPLINARIDADE.

ABSTRACT This work presents a study on transversal knowledge under of theoretical considerations, regarding the concepts of multidisciplinarity, interdisciplinarity and transdisciplinarity. The objectives are to discuss transversal knowledge and to present examples and representative schemas about these notions around disciplinary knowledge. The methodology, with a qualitative approach, is based on theoretical-methodological concepts on interdisciplinarity and transdisciplinarity, besides considering the complexity and the deleuzian rizomatic paradigm. It is proposed, therefore, a reflection on the curriculum in Vocational and Technological Education (VTE), more specifically considering the construction of relevant knowledge to higher level technologi-

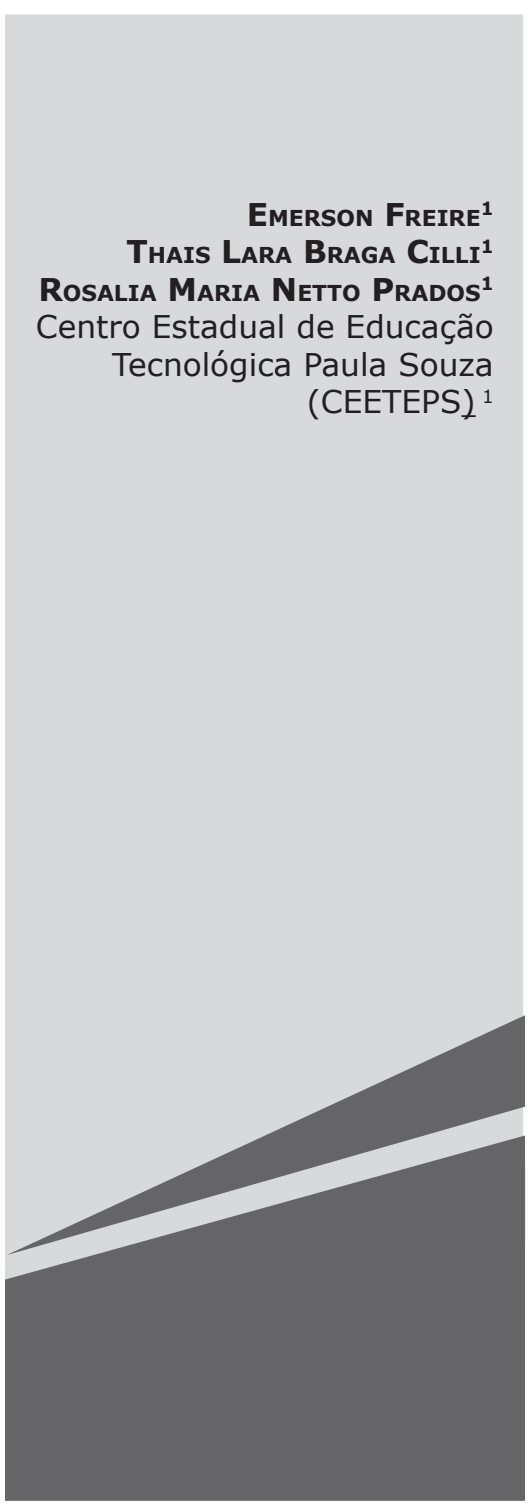


cal education. Such a discussion, from disciplinary knowledge to transversal knowledge, is relevant in professional and technological education, to facing the challenges that prevail in the current context, in view of the need for innovation, aiming at a more comprehensive about professional qualification, and the multiplicity of Knowledge.

KEYWORDS: VOCATIONAL AND TECHNOLOGICAL EDUCATION. INTEGRAL FORMATION. CURRICULUM. INTERDISCIPLINARITY. TRANSDISCIPLINARITY.

RESUMEN En este trabajo se presenta un estudio sobre el conocimiento transversal a la luz de consideraciones teóricas, sobre los conceptos de multidisciplinaridad, interdisciplinariedad y transdisciplinaridad. Tiene como objetivo debatir los conocimientos transversales y presentar ejemplos y esquemas representativos sobre estas nociones en torno al conocimiento disciplinario. La metodología, de enfoque cualitativo, se basa en conceptos teórico-metodológicos sobre la interdisciplinariedad y la transdisciplinaridad, además de considerar la complejidad y el paradigma rizomatic deleuziano. Se propone una reflexión sobre el currículo en la Educación Profesional y Tecnológica (EPT), más específicamente considerando la construcción de saberes pertinentes a la educación tecnológica de nivel superior. Este debate, desde el conocimiento disciplinario hasta el conocimiento transversal, es relevante en la educación profesional y tecnológica, en vista de los retos que se imponen en el contexto actual, frente a la necesidad de innovación, con el objetivo de una formación más integral, en la que consideremos la multiplicidad de conocimientos.

PALABRAS CLAVE: EDUCACIÓN PROFESIONAL Y TECNOLÓGICA. FORMACIÓN INTEGRAL. CURRÍCULO. INTERDISCIPLINARIEDAD. TRANSDISCIPLINARIDAD.

\section{INTRODUÇÃo}

A disciplina, conhecida no campo da educação como componente curricular, vem sendo trabalhada com novas características do currículo. Interdisciplinaridade, multidisciplinaridade e transdisciplinaridade são alguns exemplos dessas renovações em torno da disciplina (SOMMERMAN, 2011, p. 84). A proposta deste trabalho, segundo uma abordagem qualitativa, é discutir os saberes transversais e considerações sobre a multidisciplinaridade, a interdisciplinaridade e a transdisciplinaridade; e apresentar, à luz de conceitos teóricos, exemplos e esquemas representativos para a concretização do sentido dessas noções.
Para este estudo sobre transversalidade, propõe-se uma reflexão acerca do currículo de Educação Profissional e Tecnológica (EPT), bem como, são pertinentes algumas considerações a respeito do contexto em que se insere a educação superior de graduação tecnológica no Brasil. De alguma maneira, em determinados momentos históricos do país, compreendeu-se a necessidade de se habilitar técnica, social e ideologicamente diferentes grupos sociais para o trabalho, com a finalidade de responder às necessidades do bem econômico aplicável à produção, ou seja, do capital. Ressalte-se, assim, a ideia de que o desenvolvimento da educação profissional está diretamente ligado à formação educacional 
de um povo. E o currículo, portanto, atende a diretrizes de ordem política e social. No ensino superior, os princípios para um design de currículo devem atender às novas demandas sociais, humanas e profissionais (GESSER; RANGHETTI, 2011).

Nesta discussão sobre saberes transversais, é pertinente considerar os saberes disciplinares, característicos na organização do currículo, que é o instrumento norteador de práticas de formação. Tradicionalmente, de acordo com Burke (2003), no século XVII o sistema de disciplinas do saber caracterizava-se de acordo com uma organização de saberes e o tripé intelectual, na prática cotidiana das universidades europeias, seria composto de currículos, bibliotecas e enciclopédias. Da organização dos currículos, o bacharelado compunha-se de duas partes, o trivium, mais elementar: Linguagem (gramática, lógica e retórica) e o quadrivium, mais avançado: Números (aritmética, geometria, astronomia e música) (BURKE, 2003).

Pode-se verificar que o currículo se compõe de uma organização de saberes disciplinares. Segundo Gesser e Ranghetti (2011), na EPT, atualmente, o currículo deve desenvolver a capacidade do pensamento crítico, da reflexão e das teorias e da prática de determinada profissão, além de se reconhecer que escolhas (pessoais e profissionais) são sempre carregadas de valores. Por isso, tanto o currículo quanto seus fundamentos devem ser históricos e críticos.

É evidente, portanto, que seja trabaIhada uma organização do currículo para se considerarem os saberes interdisciplinares no contexto da educação profissional, uma vez que, segundo Gesser e Ranghetti (2011), a proposição de currículos para a formação profissional, atualmente, carece de vínculos com a vivência, a experiência, a história e a historicidade do conhecimento produzido e de contextos envolvidos nessa formação.
Portanto, nesta discussão são consideradas essas noções dos saberes disciplinares para os saberes transversais, cujo ponto de partida são os problemas reais e contextos das atividades profissionais da EPT. Para isso, propõem-se considerações sobre as noções de multidisciplinaridade, da interdisciplinaridade e da transdisciplinaridade, além de considerações a respeito da noção de complexidade (MORIN 2000; 2003) e o paradigma rizomático deleuziano, sugerido por Silvio Gallo (2000), a partir do conceito de rizoma na obra de Deleuze e Guattari (1995), como alternativa ao modelo disciplinar.

\section{DA DisCIPLINA AOS SABERES \\ TRANSVERSAIS}

Em tese, as disciplinas têm no ambiente educacional a função de organizar o trabalho escolar, o que é geralmente prática em todos os níveis de ensino. Apesar de fazer parte de uma estrutura, cada disciplina costuma ser independente (MACHADO, 2006, p. 115). Esse formato disciplinar, no qual os alunos são inseridos automaticamente, desde os primeiros anos de formação escolar, é entendido como constituído de minitemas autônomos.

Os alunos cursam diversas disciplinas durante os períodos escolares, habitualmente umas seguidas das outras com seus desenvolvimentos lineares respectivos intrínsecos, porém, muitas vezes, sem haver uma ligação explícita entre elas. A ideia é a de que no conjunto elas formem o conhecimento do aluno.

Segundo Leffa (2006, p. 39), portanto, na disciplinaridade, uma disciplina atua como uma caixa fechada, autossustentável e isolada de outras disciplinas. Assim, a disciplina tem relação com um objeto de estudo e tem um fim nela mesma, conforme o exemplo na Figura 1, na qual inglês e geografia realizam seus estudos separada e independentemente. 
Figura 1 - Exemplo de Disciplinaridade.
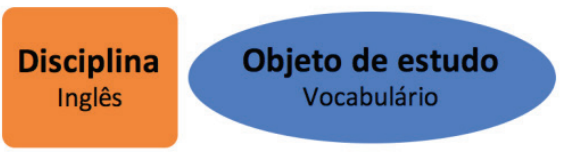

Fonte: elaborado pelos autores

Uma tentativa para minimizar essa individualidade das disciplinas é a modalidade multidisciplinar, que propõe que haja um objeto de estudo específico para conectar as disciplinas. Mesmo assim, segundo Leffa (2006), a multidisciplinaridade ainda não alcança satisfatoriamente essa conexão, pois, apesar das disciplinas terem agora algo em comum, ainda continuam isoladas, sem diálogo efetivo entre elas. Todas as disciplinas estão em torno de um mesmo tema, mas ainda assim, se forem isoladas, continuam autônomas, sem dependência umas das outras. Em outras palavras, nas de Machado (2006, p. 135), “os objetivos próprios de cada disciplina são preservados, conservando-se sua autonomia, seus objetos particulares, sendo tênues as articulações entre as mes-

\section{Disciplina \\ Geografia}

\section{Objeto de estudo}

Mapas

mas". No processo multidisciplinar, o objeto de estudo é definido primeiro para que depois as disciplinas escolham como podem utilizar o objeto dentro da sua temática.

Na Figura 2, por exemplo, o objeto de estudo é a banda inglesa The Beatles. A disciplina inglês, utilizando a temática The Beatles, pode estudar o vocabulário de algumas músicas da banda. Já a disciplina de geografia pode analisar os acidentes geográficos da Inglaterra, local de origem da banda. Dessa forma, os alunos estariam envolvidos num mesmo objeto de estudo, porém cada disciplina atuando independentemente. No entanto, o aluno iniciaria a percepção de poder unir o conhecimento de inglês com o de geografia para falar sobre The Beatles.

Figura 2 - Exemplo de Multidisciplinaridade.

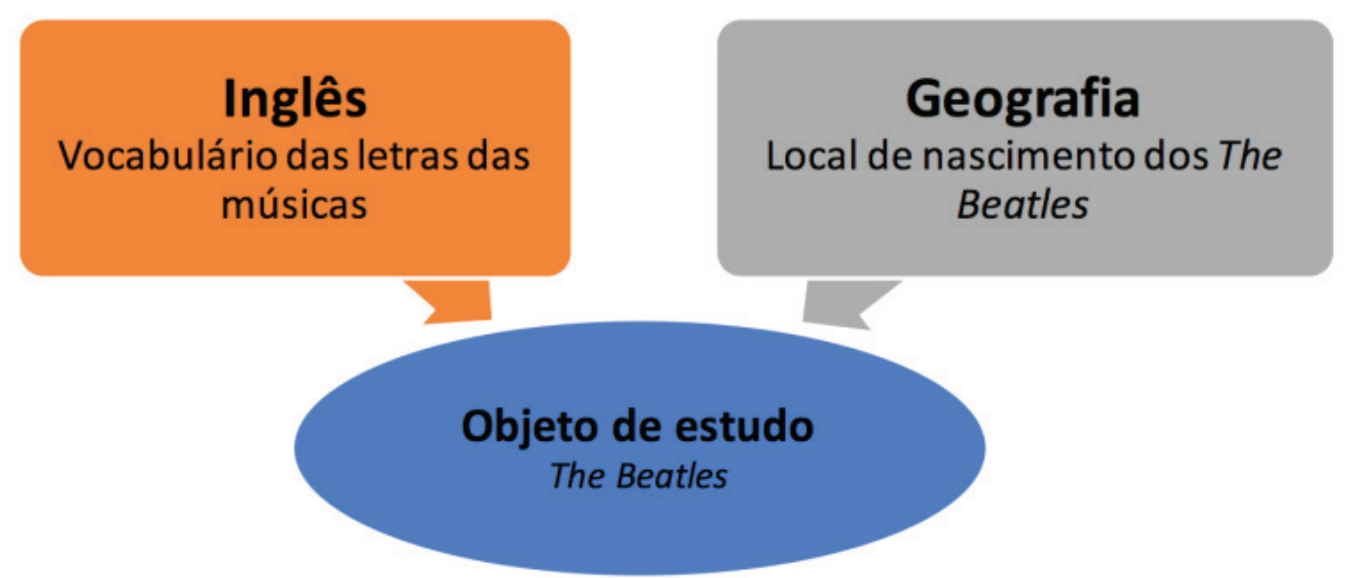

Fonte: elaborado pelos autores 
Outra modalidade para se tentar superar as limitações das disciplinas isoladas é a chamada interdisciplinaridade. Para Thiesen (2008), a interdisciplinaridade é um termo que tem diversos enfoques, como epistemológico, teórico-metodológico e pedagógico, que busca organizar os conhecimentos como um todo, sem a fragmentação no processo de produção e socialização do conhecimento. De qualquer forma, segundo o autor, não se tem uma definição final de interdisciplinaridade, pois é um processo na educação que se baseia no ato de convergir os conhecimentos das várias especialidades similares como partes de um todo, na forma colaborativa.

No modelo interdisciplinar, as disciplinas conversam entre si para chegar a um objeto de estudo, que teria um caráter de finalização do projeto e não inicialização, como no multidisciplinar. Segundo Machado, o interdisciplinar também é uma tentativa de reunir as disciplinas, antes isoladas: "a ideia de interdisciplinaridade tende a transformar-se em bandeira aglutinadora na busca de uma visão sintética, de uma reconstrução da unidade perdida, da interação e da complementaridade nas ações envolvendo diferentes disciplinas" (MACHADO, 2006, p. 117).

Na Figura 3, é possível perceber a relação entre as partes individuais para desen- volvimento cooperativo. A disciplinas inglês e geografia "conversaram" entre si para se chegar à conclusão de que seria interessante montar um vocabulário regional de cada lugar em que se fala o idioma inglês. Para saber quais são esses lugares, a disciplina de geografia precisa colaborar. Para gerar o vocabulário regional, a disciplina de inglês também necessita dar sua contribuição. E as disciplinas continuam trocando informações para se desenvolver o objeto de estudo: Vocabulário regional de inglês.

Apesar da interdisciplinaridade começar pela ligação entre as disciplinas, essa ação ainda parece insuficiente. Segundo Machado (2006), a interdisciplinaridade traria apenas um incremento entre as disciplinas, tornando-se um mero paliativo para as dificuldades de se superar o isolamento entre elas. Ainda, de acordo com o autor, é necessário "transcender os limites das disciplinas" (p. 144) e, nesse sentido, ele sugere outra abordagem, que considera mais rica: a transdisciplinaridade. Esta visa mesclar a experiência de vida do aluno àquilo que se aprende, muitas vezes, criando outras conexões não previstas pela rigidez e autossuficiência das disciplinas.

Ao discorrer sobre a integração que a transdisciplinaridade pode provocar, quando se desloca o foco para o aluno, para as pesso-

Figura 3 - Exemplo de Interdisciplinaridade.

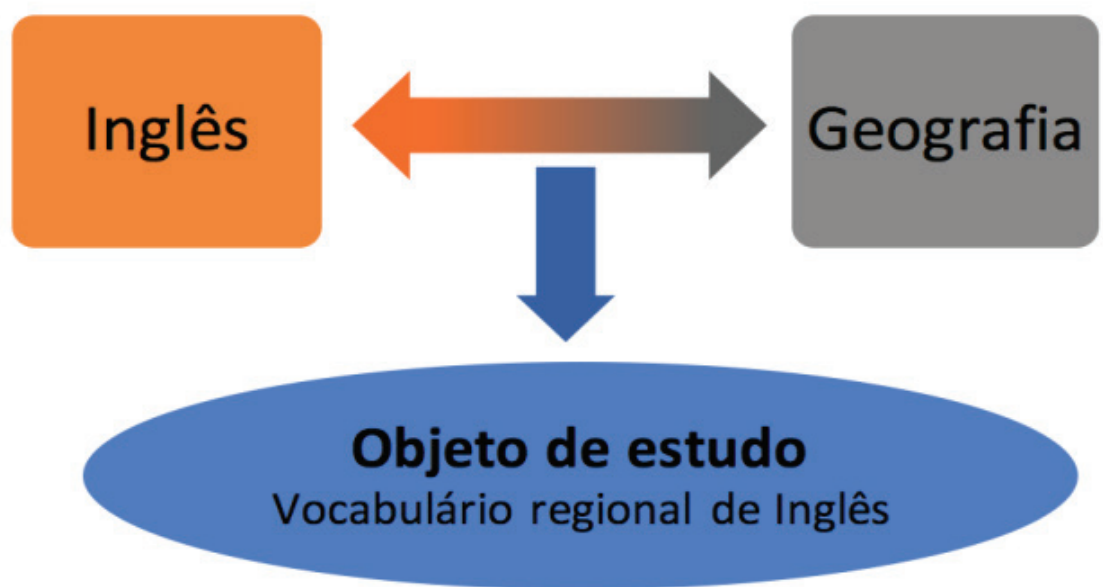

Fonte: elaborado pelos autores 
as na construção do conhecimento, Machado (2006) afirma que:

No cerne da ideia de transdisciplinaridade está o fato de que, na organização do trabalho escolar, as pessoas, e não os objetos ou os objetivos disciplinares deveriam estar no centro das atenções. É preciso ir além das disciplinas, situando o conhecimento a serviço dos projetos das pessoas (MACHADO, 2006, p. 136).

Trata-se, portanto, de um deslocamento da formação de especialistas em determinadas disciplinas para outra que visa fomentar o conhecimento para o social, o que traz um desafio muito maior ao ambiente educacional em seus diferentes estágios e modalidades. Como diz Morin, a esse respeito, "no que concerne à transdisciplinaridade, trata-se frequentemente de esquemas cognitivos que podem atravessar as disciplinas, às vezes com tal virulência, que as deixam em transe" (MORIN, 2003, p. 115).

Uma das preocupações centrais de Edgar Morin (2000, 2003), que se reflete na educação diretamente, como se sabe, é a complexidade do pensamento a partir dos desafios originários da sociedade-mundo, como ele a chama em alguns escritos, na era digital e suas características de expansão descontrolada da geração de informações. A assimilação, manutenção e, de certa forma, o "bom aproveitamento" desse volume informacional requer, na ótica do autor francês, uma formação integral, capaz de conectar o ensino tecnocientífico especializado com as questões mais abrangentes, de cunho social, ou seja, não restringir o pensamento, mas considerá-lo em sua complexidade, na relação local-global.

Morin (2000) não utiliza a palavra transversalidade diretamente, prefere transdisciplinaridade. Porém, em relação à última, sua concepção se aproxima daquela que será vista posteriormente aqui em relação à transversalidade. Por um lado, ao caracterizar a transdisciplinaridade, por esquemas cognitivos que atravessam as disciplinas, sendo essa prática, menos difundida em relação às outras, Morin a considera de extrema importância para a formação do aluno, pois de nada adiantam vários saberes parcelados sem se conseguir uni-los em uma configuração que potencialize sua utilidade em dado contexto. Por outro lado, embora mantenha a parte disciplina no termo, Morin não somente acrescenta o prefixo "trans", mas salienta que, em função desse atravessar dos mais diversos conhecimentos na composição do pensar complexo, é preciso "ecologizar" as disciplinas, isto é, "considerar tudo o que lhes é contextual, aí incluídas as condições culturais e sociais" (MORIN, 2000, p. 79).

Todo problema passa, de certa forma, pela compartimentalização do conhecimento, cujo fenômeno é constituinte de um todo maior, a especialização do saber, como expõe Silvio Gallo (2000). Quando Gallo, por sua vez, propõe a possibilidade de pensar as bases de uma educação não-disciplinar, parte da seguinte pergunta:

As propostas interdisciplinares como todas as suas adjetivações e mesmo os outros conceitos próximos a ela, de multidisciplinaridade e transdisciplinaridade - surgiram exatamente para possibilitar esse livre trânsito pelos saberes, rompendo com suas fronteiras e buscando respostas aos assuntos complexos como os ecológicos e os educacionais, por exemplo. Devemos, portanto, perguntar: a interdisciplinaridade dá conta de romper com as barreiras entre as disciplinas? (GALLO, 2000, p. 28).

E ele mesmo responde: "temo que não: embora ela possa significar um grande avanço em relação à disciplinarização pura e simples, não é, porém, um rompimento definitivo com as disciplinas" (GALLO, 2000, p. 28).

A resposta negativa de Gallo é compreensiva. Leitor atento de Deleuze, de Guat- 
tari e de Foucault, ele não perde de vista o caráter de controle e poder exercido pelas disciplinas. Não se trata apenas do controle acerca do aprendizado, mas também sobre o comportamento: "disciplinar o aluno é também fazer com que ele perceba seu lugar social" (GALLO, 2000, p. 24). Desde a cartografia da sala de aula aos mecanismos de exame, passando pelo aparelho burocrático escolar.

De qualquer modo, para que a transversalidade possa acontecer, é necessário algo que a provoque, elementos concretos que, de alguma forma permitam, num primeiro momento ao menos, perceber que algumas características dessa conceituação estejam aparecendo no ambiente educacional, manifestando-se de forma factual e que exigem uma mudança de percepção sobre a formação.

Nesse caso, algumas alternativas/iniciativas que têm a transversalidade, enquanto foco de discussão/reflexão/prática de ensino, podem ser detectadas e estudadas. Neste artigo, parte-se de duas abordagens possíveis, cada qual com uma experiência acadêmica de exemplo: uma, a partir do que é descrito nos Parâmetros Curriculares Nacionais, PCNs (BRASIL, 1998), em que o transversal aparece enquanto tema, ou temas a serem trabalhados de forma pragmática; outra, proveniente da leitura de Silvio Gallo (2000), a respeito da obra dos filósofos franceses Deleuze e Guattari. Ou seja, a partir do campo da filosofia da educação, em que o autor propõe que se pense uma educação não-disciplinar, em que o transversal apareça enquanto saber, enquanto fundamento para se gerar conhecimento, enquanto uma mudança de paradigma a ser vislumbrada.

No primeiro caso, escolheu-se o trabaIho dos autores Silva, Rufino e Darido (2013), por trabalharem com a ideia de tema transversal, conforme preconizado pelos PCNs. No segundo, Marques, Marques e Sarraipa (2010), por partirem também da teoria dos filósofos franceses e trabalharem na linha do saber transversal.

\section{A Transversalidade como tema SEGUNDO OS PCNS}

A transversalidade aparece citada pelos PCNs como uma forma de abordagem que visa a uma educação fundamental voltada à cidadania e às questões sociais trabalhadas a partir da reflexão com os alunos. A indicação dos PCNs é que a transversalidade contenha temas predefinidos, ou seja, a forma de se trabalhar se daria por meio de um (ou mais) desses temas que atravessariam as demais áreas e disciplinas, sem se constituírem enquanto tais. Desse modo, a regionalidade e os acontecimentos locais podem ser contextualizados e contemplados, ampliando-se a diversidade de temas possíveis.

O conjunto de temas proposto pelos PCNs, para o ensino fundamental e médio, engloba Ética, Meio Ambiente, Pluralidade Cultural, Saúde, Orientação Sexual, TrabaIho e Consumo. A esse conjunto de temas foi fornecido o nome de temas transversais (BRASIL, 1998, p. 25). Assim, a proposta de um tema transversal é a utilização de uma temática que possa abordar alguns dos temas do conjunto citado, para se discutir a ética da convivência humana, relação com a vida social, construção da cidadania e democracia, entre outros.

Os temas transversais dos PCNs procuram tratar de processos vividos pelos alunos, considerando-se que, assim como em qualquer experiência de vida, vários conhecimentos são envolvidos. Nesse sentido, é necessário o envolvimento e engajamento das diversas áreas para se trabalhar um tema transversal (BRASIL, 1998). Para exemplificar: a questão ambiental não é exclusiva da geografia e, assim sendo, para uma abordagem efetiva é necessário o conhecimento da História, Ciências Naturais, Demografia, Economia, entre outros (BRASIL, 1998, p. 27).

A proposta de temas transversais, conforme os PCNs, define-se então em quatro pontos basilares: 
a) os temas não constituem novas áreas, pressupondo um tratamento integrado nas diferentes áreas;

b) a proposta de transversalidade traz a necessidade de a escola refletir e atuar conscientemente na educação de valores e atitudes em todas as áreas, garantindo que a perspectiva político-social se expresse no direcionamento do trabalho pedagógico; influencia a definição de objetivos educacionais e orienta eticamente as questões epistemológicas mais gerais das áreas, seus conteúdos e, mesmo, as orientações didáticas;

c) a perspectiva transversal aponta uma transformação da prática pedagógica, pois rompe o confinamento da atuação dos professores às atividades pedagogicamente formalizadas e amplia a responsabilidade com a formação dos alunos. Os Temas Transversais permeiam necessariamente toda a prática educativa que abarca relações entre os alunos, entre professores e alunos e entre diferentes membros da comunidade escolar;

d) a inclusão dos temas implica a necessidade de um trabalho sistemático e contínuo no decorrer de toda a escolaridade, o que possibilitará um tratamento cada vez mais aprofundado das questões eleitas. Por exemplo, se é desejável que os alunos desenvolvam uma postura de respeito às diferenças, é fundamental que isso seja tratado desde o início da escolaridade e que continue sendo tratado cada vez com maiores possibilidades de reflexão, compreensão e autonomia. Muitas vezes essas questões são vistas como sendo da "natureza" dos alunos (eles são ou não são respeitosos), ou atribuídas ao fato de terem tido ou não essa educação em casa. Outras vezes são vistas como aprendizados possíveis somente quando jovens (maiores) ou quando adultos. Sabe-se, entretanto, que é um processo de aprendizagem que precisa de atenção durante toda a escolaridade e que a contribuição da educação escolar é de natureza complementar à familiar: não se excluem nem se dispensam mutuamente (BRASIL, 1998, p. 28).

Em suma, trata-se de temas que não se tornam novas áreas, mas que interligam as áreas já existentes, que proponham uma reflexão aprofundada, que sejam permissivos à atuação dos professores na atribuição de responsabilidade da formação dos alunos e que impliquem um trabalho contínuo e aprofundado, de acordo com a escolaridade dos alunos, complementando o papel familiar. Desse modo, a transversalidade, segundo os PCNs, busca a relação entre o aprender sobre a realidade e o aprender na realidade e da realidade. Portanto, a utilização de temas transversais exige uma postura ativa diante de problemas fundamentais e urgentes da vida social, requerendo reflexão a respeito do ensino e da aprendizagem dos valores, procedimentos e concepção a eles relacionados (BRASIL, 1998, p. 35).

A exploração de temas transversais proposta pelos $\mathrm{PCNs}$ pode ser observada no estudo realizado com a utilização da capoeira no ensino fundamental por Silva, Rufino e Darido (2013). Os autores usaram, como exemplo, a capoeira como tema transversal apropriando-se de propostas pedagógicas pautadas na diversidade cultural, na historicidade, entre outras (p. 88). Na visão dos autores, eles obtiveram sucesso ao sugerirem a utilização da capoeira como tema transversal, dada a sua abordagem ser com diversas disciplinas, pelo seu caráter histórico, saudável, artístico e ético. Neste estudo, relataram que a maioria dos professores de diferentes disciplinas concordou que a capoeira poderia sim ser um tema transversal, e que eles poderiam abordá-la em suas disciplinas seguindo as característi- 
cas citadas pelos PCNs: Ética, Meio Ambiente, Pluralidade Cultural, Saúde, Orientação Sexual, Trabalho e Consumo, conforme Figura 4. É possível observar que as disciplinas e o que será estudado estão bem definidos e se sabe qual o rumo que o tema transversal terá durante o seu desenvolvimento.

Figura 4 - Exemplo de Transversalidade conforme abordado pelos PCNs.

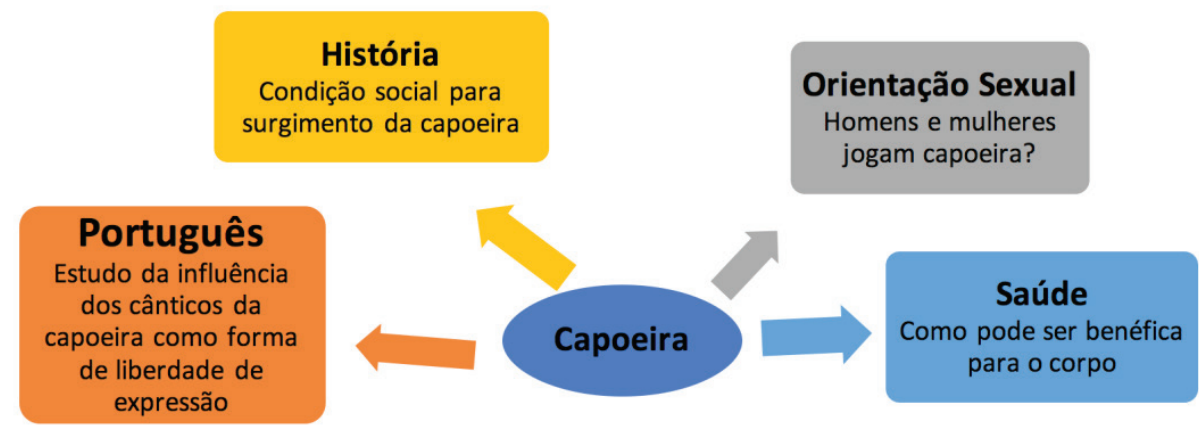

Fonte: elaborado pelos autores, a partir de Silva, Rufino e Darido (2013)

Apesar de se chamar transversal, o proposto pelos $\mathrm{PCN}$ se assemelha ainda à prática multidisciplinar, em que as disciplinas ainda são vistas isoladamente e, somente em alguns momentos aparece o caráter transversal, principalmente quando o aluno tem conhecimento prévio do tema em questão ou, quando no mínimo ele é dado, é predefinido. Pelos PCNs, a transversalidade aparece quando são abordados os assuntos preestabelecidos, conectando a disciplina com a realidade do aluno, por exemplo, a capoeira, como transversal, conectando o português com a liberdade de expressão que um aluno deseja ter em sua vida.

Em outras palavras, partindo da abordagem de Morin (2000), sobre a transdisciplinaridade, e das considerações de Gallo (2000), a respeito das limitações da interdisciplinaridade e suas derivadas, já vistas, o transversal não se configuraria enquanto tema disciplinar propriamente dito, mas estaria mais próximo de um saber, ou da constituição de um saber em toda a sua complexidade, em seu desenvolvimento, enfim, da necessidade de uma mudança de concepção em direção à teoria do conhecimento, em relação ao processo educa- tivo num sentido amplo. Para observar-se um tipo de conhecimento, enquanto saber transversal, necessita-se de um exercício, nada fácil, de olhar para além da disciplinaridade e suas derivadas e iniciar um processo de mudança de percepção sobre a constituição do conhecimento, incluindo elementos socioculturais, ou ainda melhor dizendo, tecnossociais contemporâneos em sua composição.

\section{A Transversalidade como possível Saber Não Disciplinar}

Gallo (2000) propõe uma discussão sobre transversalidade a partir da filosofia da educação, da teoria do conhecimento, da constituição de um saber. Seu ponto de partida é o conceito de rizoma, tecido por Deleuze e Guattari (1995) no primeiro capítulo do livro Mil Platôs: capitalismo e esquizofrenia. Gallo (2000) inicia com as metáforas da árvore e do rizoma, ambos do campo da botânica. $\mathrm{A}$ árvore é metaforicamente simbolizada como uma fonte de conhecimento: a árvore do saber; em Burke (2003), árvore do conhecimento. Ela é comumente utilizada para entender os vários campos do saber, sendo a filosofia 
como um tronco, a curiosidade como adubo e as especializações como galhos.

Já rizoma é um termo da botânica para definir quando os caules se desenvolvem subterraneamente e podem se ramificar em demasia. Outra característica do rizoma é a facilidade em brotar e produzir novas plantas.

Para mostrar as características de uma possível proposta transversal, Gallo (2000) tenta romper com a árvore do saber privilegiando em seu lugar o rizoma, e com isso cria um termo que ele chama de paradigma rizomático. Tal paradigma propõe contrariar a tradicional árvore do saber: uma árvore cresce de forma vertical e os galhos saem de um caule, assim como a estrutura curricular se fundamenta em uma base também verticalizada, com galhos que não se conectam entre si, isto é, disciplinas e saberes que saem de uma base em direções opostas e independentes. O rizoma, por sua vez, acontece escondido, por baixo da terra, e vai se expandindo sem controle, o que seria próximo à função de um saber transversal, provocando o desenvolvimento de conhecimentos sem a total consciência do aluno, realizando novas conexões entre a experiência de vida e as disciplinas, sem hierarquias.

$\mathrm{O}$ autor comenta que o paradigma rizomático foi oriundo da botânica e da filosofia, como origem na preocupação dos filósofos Gilles Deleuze e Félix Guattari em relação aos tratamentos terapêuticos da psicanálise. Em uma terapia existe transferência entre paciente e terapeuta, e como é de forma individualizada, torna-se hierárquica em certo sentido. Para se trabalhar coletivamente e de uma forma horizontalizada, Guattari propôs a transversalidade como forma de atravessar as relações entre as pessoas. Mais tarde, segundo o autor, esse conceito foi estendido para o conhecimento e surgiu a ideia de saberes transversais, que seriam saberes que perpassam diversos campos de conhecimento, sem ser exclusivo de nenhum deles (GALLO, 2000).

No livro Mil Platôs, Deleuze e Guattari (1995) comentam sobre uma realidade que ultrapassa a distinção entre consciência e inconsciência, que não supõe unidade, totalida- de e nem um sujeito. Tudo são processos que surgem na realidade, o que eles chamam de multiplicidades. Entre os princípios das multiplicidades, citam o seu caráter rizomático, por compor uma dualidade de oposição ao modelo arbóreo. De forma bem resumida, as características, ou os princípios, do rizoma, segundo os filósofos, seriam: i e ii) o princípio de conexão e heterogeneidade: qualquer ponto do rizoma pode-se conectar a outro ponto; iii) multiplicidade: quando não se tem mais relação como sujeito ou objeto; iv) ruptura a-significante: se um rizoma é interrompido, ele retoma por outro caminho; v e vi) a cartografia e decalcomania: um rizoma não tem uma estrutura definida.

Esses princípios foram trabalhados por Gallo (2000) e trazidos para a área da educação, formando um possível paradigma rizomático a ser buscado, descritos resumidamente a seguir, e que serão utilizados para ilustrar esta definição. Conexão: qualquer disciplina pode se conectar com outras, isto é, não serem isoladas como se fossem minicursos independentes; Heterogeneidade: as disciplinas e corpo docente não estariam em uma hierarquia, o que seria uma nova ideologia de horizontalidade; Multiplicidade: possibilidade de novos temas principais e norteadores, de acordo com cada necessidade e cada realidade; Ruptura A-significante: nenhum planejamento de rota é definitivo, isto é, o currículo altera o caminho que está seguindo como se fosse sempre um rascunho; Cartografia: pode-se iniciar e acessar por diversos pontos e não somente por um tronco principal, assim como pode-se terminar o caminho de forma diferente e individualizada; Decalcomania: realizando um estudo sobrepondo um currículo rizomático sobre um currículo arbóreo pode-se possibilitar novas multiplicidades.

Ao se destacarem as características do paradigma rizomático deleuziano, percebe-se que o resultado pode ser inesperado, principalmente quando se atenta para as características de cartografia e ruptura a-significante. A característica de multiplicidade propõe que o objeto de estudo possa ser também o prota- 
gonista e é ele que determinará quais disciplinas ou conhecimentos serão necessários para resolver o problema, de acordo com cada aluno. Já com a decalcomania é possível perceber que uma nova proposta, a rizomática, em conjunto com as disciplinas existentes, pode possibilitar novos conhecimentos. A interligação das disciplinas antes isoladas também aparece como conexão.

A heterogeneidade, como uma característica do paradigma rizomático, permite a conexão inicial com a ideia de transversalidade, pois o aproveitamento do conhecimento que o aluno já tem, segundo sua vivência e seu ambiente de vida, cria uma horizontalidade de conhecimento mesclado às disciplinas e aos outros conhecimentos para além delas. Essa ruptura da unidade da disciplina para invadir a realidade do aluno inicia um trabalho horizontal de conhecimento que antes não aconteceria, visto que mesmo na prática interdisciplinar o conhecimento costuma ser somente vertical, de professor para aluno. Nesse caso, o conhecimento pode iniciar no aluno e vir da sua realidade, alterando a forma de se trabalhar um tema dentro da escola. Essa ampliação horizontal e que frutifica, além da sala de aula, é um dos princípios da transversalidade:

As propostas de uma interdisciplinaridade postas hoje sobre a mesa apontam, no contexto de uma perspectiva arbórea, para integrações horizontais e verticais entre as várias ciências; numa perspectiva rizomática, podendo apontar para uma transversalidade entre as várias áreas do saber, integrando-as, senão em sua totalidade, pelo menos de forma muito mais abrangente, possibilitando conexões inimagináveis por meio do paradigma anterior. Assumir a transversalidade é transitar pelo território do saber como as sinapses viajam pelos neurônios de nosso cérebro, uma viagem aparentemente caótica que constrói seu (s) sentido (s) à medida que desenvolvemos sua equação fractal (GALLO, 2000, p. 33).

É, portanto, uma mudança de perspectiva que propõe Gallo, a partir de Deleuze e Guattari, é a capacidade de perceber um frequente atravessar das disciplinas por esquemas cognitivos, com tal virulência, como disse Morin, a ponto de as deixarem em transe, ou em xeque. É como comentou também Morin (2003) que, ao se tratar as disciplinas isoladamente, cria-se uma hiperespecialização, isto é, uma pessoa muito especializada em um assunto, mas incapaz de relacionar esse conhecimento com outros a seu redor.

No fundo, um processo de formação incapaz de lidar com a complexidade do pensamento, dadas as condições tecnossociais contemporâneas. Esse isolamento é um retaIhamento que dificulta a conexão entre tudo o que se aprende e também entre a própria experiência de vida. A globalidade é complexa e, por isso, exige conexões complexas.

Nesse sentido, para essa conexão acontecer, é necessário um saber condutor, não um tema ou disciplina apenas, um conhecimento que estimule a procura e oriente metodologicamente como aplicar a relação entre o objeto de estudo e aquilo que é necessário para se desenvolver. Um saber que não seja uma disciplina específica, mas ao contrário, que seja desvinculado de qualquer disciplina, um assunto independente de qualquer currículo, mas ainda assim colaborador para a ligação entre disciplinas e o conhecimento individual. Portanto, para se trabalhar a transversalidade é necessário um saber, chamado transversal, que estimule a integração de conhecimentos.

Essa dimensão foi nomeada como saber transversal rizomático deleuziano no trabalho de Marques, Marques e Sarraipa (2010). ${ }^{1}$ Es-

1 Embora os autores citados optaram por saber transversal rizomático "deleuziano", entende-se aqui que o melhor seria "deleuze-guattariano", inclusive porque no encontro entre os dois filósofos o conceito de transversalidade é mais proveniente das experiências de Félix Guattari em La Borde. 
sas autoras comentam que trabalhar saberes transversais dessa forma significa o "abandono de verticalismos e horizontalismos da árvore em favor daqueles fluxos que podem tomar qualquer direção, sem hierarquia definida de antemão; significa a possibilidade de pulverização, a multiplicidade, as policompreensões infinitas, a diferença produzindo diferenças" (p. 230). Aqui predomina o espaço para a criação de outras perspectivas como princípio, expansão do conhecimento e de aplicações, de outras conexões, não se distinguindo as partes ou disciplinas como sendo de utilidade exclusiva da escola ou de certa disciplina. O conhecimento é aplicado com outros conhecimentos formando um saber para a vida, sem distinção do que seria somente para a escola e o que seria para o cotidiano do aluno.

As autoras comentam, em seus relatos que, ao trabalharem o texto Morte e Vida Severina, de João Cabral de Melo e Neto, além das maneiras tradicionais de se abordar esse livro, como a geografia do Nordeste, a história dos retirantes e a montagem da peça teatral, assuntos inesperados, como a migração e o sentimento dos retirantes, apareceram nos diálogos. Assuntos esses não vinculados a qualquer disciplina previamente pensada e que não eram esperados. Havia um objeto de estudo como eixo norteador: a leitura do texto, porém na medida em que os alunos foram se apropriando do texto, foram realizadas novas conexões e relações inusitadas, segundo as autoras.

Outro exemplo, também das autoras, foi o início dos estudos com uma sala de aula do $4^{\circ}$. ano do ensino fundamental, a partir do livro intitulado Lampião e Lancelot, do autor Fernando Vilela, publicado em 2006. O livro conta sobre os dois personagens por meio da literatura de cordel, xilogravura e cores relacionadas propositalmente: o prateado remetendo à época medieval de Lancelot e o cobre dourado a Lampião.

A partir da exploração desse livro e suas cores começou a investigação histórica desses personagens, passando para a escrita de cordel, a arte manual da xilogravura, à diversi- dade de como Lampião é representado, à história do mestre Vitalino, importante ceramista popular brasileiro, que representa Lampião em suas obras, à discussão de assuntos como medo, coragem, morte e vida, entre outros. Nesse ponto, foi introduzido o final do texto Morte e Vida Severina.

Porém, com a curiosidade e sentimento de exploração aguçados nos alunos, eles leram todo o texto por livre iniciativa. Reiniciando o ciclo, agora com o texto, novos assuntos apareceram, como as explorações das obras referentes ao sertão de Portinari, onde existe a caatinga e o mandacaru e o questionamento de desde que época não se tem água no Nordeste. Nesse exemplo, é difícil distinguir com precisão o que é pertencente a história, artes visuais, português ou geografia. $\mathrm{Na}$ constituição de um saber transversal, seja o livro de Vilela ou o texto Morte e Vida Severina, a exploração deles levou os alunos a um processo de conhecimento aprofundado e a buscar auxílio nas outras disciplinas e outros saberes para complementar e esclarecer o que eles estavam explorando.

$\mathrm{Na}$ Figura 5, de forma simplificada, exemplifica-se como aconteceu a transversalidade segundo Marques, Marques e Sarraipa (2010) e se verifica que o percurso de um saber transversal rizomático deleuziano não é previsível e se desvincula das disciplinas tradicionais.

Se for aplicado o mesmo livro de Lampião e Lancelot em outra classe, mesmo sendo também de $4^{\circ}$. ano do ensino fundamental, na mesma escola e pelos mesmos professores, as propostas, os saberes e o que será discutido serão diferentes do que aconteceu, pois os conhecimentos e curiosidades provindos dos alunos serão diferentes, gerando um novo percurso de conhecimento.

Assim, não se trata de haver ou de se encontrar somente um saber transversal. Quanto mais saberes desse tipo, melhor e maiores serão as conexões possíveis, maior a possibilidade de se criar rizoma, pois são os princípios de conexão e heterogeneidade em pleno funcionamento. Trata-se de trabalhar com multi- 
Figura 5 - Exemplo de transversalidade rizomática deleuziana.

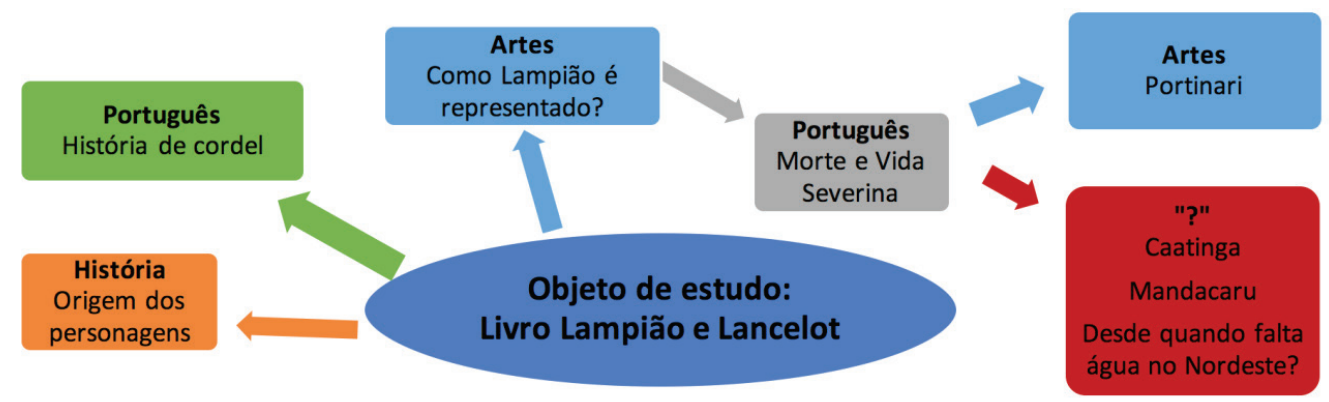

Fonte: elaborado pelos autores, a partir de Marques, Marques e Sarraipa (2010)

plicidades, não com grades. Uma característica relevante, assim, é que o saber transversal "atravessa diferentes campos de conhecimento, sem identificar-se necessariamente com apenas um deles" (GALLO, p. 32, 2000).

\section{Educação Profissional e Tecnológica e o Saber Transversal}

Essa pluralidade de possibilidades de resultados, a utilização dos conhecimentos e vivências dos alunos e a facilitação de integração com as disciplinas existentes podem ser os motivadores da escolha pela transversalidade rizomática deleuziana no ambiente educacional, incluindo, por suas especificidades estratégicas para a dinâmica sociopolítica, a Educação Profissional e Tecnológica (EPT). Bem como, outras áreas, a EPT vem enfrentando os desafios crescentes, em virtude da complexidade exigida para a produção de conhecimento na atualidade, com a particularidade de enfrentá-los de maneira muito próxima, por estar diretamente ligada ao fazer tecnológico e seus consequentes impactos socioculturais.

A EPT, no Brasil, abrange os cursos de formação inicial ou qualificação profissional, educação profissional técnica de ensino médio e educação profissional tecnológica de graduação, de acordo com a Lei de Diretrizes e Bases da Educação Nacional n. 9.394, de 20 de dezembro de 1996. Existem diversas insti- tuições que oferecem educação tecnológica, como instituições privadas de ensino superior, institutos federais e as estaduais como, no caso do Estado de São Paulo, o Centro Paula Souza.

Na EPT, várias alterações aconteceram, desde os anos 1970, como o aumento da oferta de cursos, inclusive pela demanda por profissionais que sejam capazes de produzir novos conhecimentos e processos, permitindo o desenvolvimento de inovações. Nessa trajetória da EPT, desde seu início, como apontam vários autores (MANFREDI, 2003; CIAVATTA e RAMOS, 2012; MACHADO, 2008; FREIRE, 2012) sempre houve um embate entre a formação para o mercado de trabalho, que se valeria mais de conhecimentos específicos, versus uma formação para o mundo do trabalho, mais abrangente, integral.

Machado (2008) salienta como uma das características preponderantes do tecnólogo a de ser um profissional com potencial criativo e com necessidade de uma visão geral dos processos. Zanona, por sua vez, enfatiza a necessidade de ampliação da educação tecnológica para complementar a educação formal e normativa. Afinal:

[...] engenheiros civis aprendem a construir estradas, detêm o conhecimento sobre materiais, condições topográficas, drenagem local, estabilidade, tecnologia adequada para construção, mas que importância é 
dada à formação ampla, para análise, a reflexão, para o questionamento? (ZANONA, 2015, p. 68).

Nesse sentido, mais do que a formação estritamente técnica de qualidade, é necessário que se amplie o conjunto de conhecimentos que possibilitem uma visão crítica de sua atuação por parte do profissional. Ciavatta e Ramos argumentam que na formação de um profissional, do eixo tecnológico ou não, os conhecimentos oriundos das especificidades daquela profissão não são suficientes para a compreensão das relações sociais de produção:

Por isto a defesa da integração desses conhecimentos [específicos] com os de formação geral. Mesmo que os processos produtivos em que se pode exercer uma profissão sejam particularidades da realidade mais ampla, é possível estuda-los em múltiplas dimensões - econômica, social, política, cultural e técnica, dentre outras - de forma que, além dos conhecimentos específicos, os de formação geral tornam-se também uma necessidade (CIAVATTA e RAMOS, 2012, p. 17).

Mais uma vez, as discussões sobre a complexidade do pensamento (MORIN, 2003), com suas múltiplas dimensões, salientadas pelas autoras na citação anterior, e a constituição de saberes transversais, que tentam superar a disciplinaridade (GALLO, 2000), aparecem como primordiais.

Para trabalhar aspectos diferentes na EPT visando a uma formação geral, enquanto uma necessidade, num primeiro momento pode-se pensar na interdisciplinaridade como fazem, de certa forma, as próprias autoras (CIAVATTA e RAMOS, 2012). Na verdade, elas estão se opondo, de alguma maneira, ao modelo do currículo por competências que, embora pareçam coadunar-se com essa necessidade de superar as disciplinas, acabam por sinalizar uma adaptabilidade ao mercado de trabalho apenas, por meio de especialização prática disciplinar.

Segundo esse modelo, dizem as autoras, a "ação competente no trabalho é guiada por um tipo de saber próprio que é síntese entre o conhecimento teórico aprendido na formação e as experiências" (CIAVATTA e RAMOS, 2012, p. 17). No entanto, o que é enfatizado por elas, de fato, é a prática como a própria metodologia de ensino, de forma que a prática profissional se torne organizadora do currículo disciplinarmente.

Haveria aí, na metodologia das competências, um problema na própria concepção de teoria e prática. Não se trata de um "saber fazer algo" da experiência que se restringirá, em certo sentido, receber o carimbo de uma teoria, como chancela. O que está em jogo é uma reelaboração da composição dos saberes que deem conta da complexidade tecnossocial e que, em última instância, tenham caráter estratégico.

Para Scachetti (2012), uma necessidade premente é se pensar em termos do "saber-fazer", com hífen: "[...] trata-se de acentuar a necessidade de uma nova relação entre os saberes e as práticas no mundo contemporâneo, em que não podemos mais separar o saber e o fazer ou, se quisermos, a teoria e a prática", ou seja, a necessidade de reunificação das práticas e dos conhecimentos técnicos, sociais, estéticos e políticos (p. 91).

Nesse caso, ser interdisciplinar pode não bastar, como já se viu, o que é válido também para a EPT. Se ser interdisciplinar não é suficiente e é necessário uma nova relação entre os saberes e as práticas do mundo atual. $\mathrm{O}$ desafio à EPT está justamente em se criarem formas de atuar englobando a colaboração de diversas áreas na construção de tecnologias, cujos impactos socioculturais mudam, dependendo da articulação e concepção desses saberes no próprio processo do fazer tecnológico.

Ciavatta também expõe sobre a formação do aluno em relação ao envolvimento entre os conhecimentos globais, tecnologias e socialização "para uma convivência com o 
planeta e a humanidade, de modo a preservar a vida" (CIAVATTA, 2006, p. 913). Essa é uma preocupação para o mundo de hoje e mostra como o desenvolvimento tecnossocial precisa transparecer na educação, não se restringindo à questão da empregabilidade de curto prazo conquistada via a especialização disciplinar somente.

Uma das caraterísticas da formação do tecnólogo é trabalhar muitas vezes com tecnologias simbólicas, que extrapolam o domínio técnico e exigem capacidade perceptiva e intelectual do contexto social em que atua, conforme salienta Machado (2008):

Os tecnólogos podem se ocupar de tecnologias simbólicas, quando se debruçam sobre processos e modos de percepção e de intelecção, utilizam modelos teóricos para a concepção da realidade natural e social e de avaliação, recorrendo aos signos, códigos, indicadores, parâmetros, bancos de dados, conceitos (MACHADO, 2008, p. 22).

Todavia, evidentemente, não se trata apenas de ensinar uma série de métodos isolados e acreditar que sejam suficientes para o desencadeamento do saber transversal e, por conseguinte, obter como resultados em inovações tecnológicas substanciais e sustentáveis. Freire (2012, p. 6), a partir das experiências em sala de aula, salienta que elaborar uma problemática e pedir aos alunos para simplesmente criar ou inventar é algo fácil de se fazer e que, no entanto, comumente o resultado não é inovador. Trata-se de dar condições para que a transversalidade aconteça de fato e fomente o processo inventivo.

\section{CONSIDERAÇões FinAis}

Nesse sentido, a ideia de saberes transversais, trazida por Silvio Gallo (2000), a partir dos textos de Deleuze e Guattari, contribui para se pensar também a educação profissional e tecnológica, pois se coaduna com essa necessidade por inovação em toda a sua complexidade (não apenas a mercadológica) e os seus pressupostos descritos em documentos como os próprios planos pedagógicos dos cursos, visando-se a uma formação mais abrangente, uma vez que a transversalidade trabalha o respeito às diferenças, construindo possíveis trânsitos pela multiplicidade dos saberes sem integrá-los artificialmente.

Como apontam os estudos de Edgar Morin (2000, 2003), os princípios norteadores da inteligibilidade do complexo foram forjados a partir da cibernética e da teoria da informação, transformando as relações socioculturais e a produção de conhecimento. Trata-se de substituir, segundo o autor, um pensamento que isola e separa por um pensamento que distingue e une, um pensamento redutor por um pensamento do complexo, utilizando o sentido originário do termo complexus: o que é tecido junto (MORIN, 2003, p. 89). Morin acentuará, ainda, que para se pensar o ensino é necessário começar a considerar os efeitos da compartimentação dos saberes, por um lado, e a difícil atividade de articulá-los, por outro.

Guardadas as devidas diferenças entre os autores, de certa forma, é nesse sentido que Gallo (2000) procura propor uma visão de educação não disciplinar, não compartimentada, para a qual ele considera fundamental o conceito de transversalidade, de saber transversal. Face aos desafios tecnossociais complexos da atualidade, que tornam a superação da fórmula da formação disciplinar, esses autores podem ajudar substancialmente a iniciar esse debate no âmbito e a permitir que se construam experiências promissoras nesse sentido dentro da educação profissional e tecnológica. 


\section{REFERÊNCIAS}

BRASIL. Secretaria de Educação Fundamental. Parâmetros curriculares nacionais: terceiro e quarto ciclos: apresentação dos temas transversais / Secretaria de Educação Fundamental. Brasília: MEC/SEF, 1998.

BURKE, Peter. Uma História Social do Conhecimento. De Gutenberg a Diderot. Rio de Janeiro: Zahar, 2003.

CIAVATTA, Maria. Os centros federais de educação tecnológica e o ensino superior: duas lógicas em confronto. In: Educ. Soc., Campinas, v. 27, n. 96, out. 2006.

. RAMOS, Marise. A “era das diretrizes”: a disputa pelo projeto de educação dos mais pobres. In: Revista Brasileira de Educação, v. 17, n. 49, jan./abr. 2012.

DELEUZE, Gilles. GUATTARRI, Félix. Mil platôs: capitalismo e esquizofrenia, v. 1. Rio de Janeiro: Editora 34, 1995.

FREIRE, Emerson. Tecnólogo e Mercado: uma relação a ser revisitada. In: ALMEIDA, Ivanete Bellucci Pires; BATISTA, Sueli Soares dos Santos (Org.). Educação Tecnológica: reflexões, teorias e práticas. São Paulo: Paco Editorial, 2012.

. Tecno-estética e formação: especulações iniciais a partir de Simondon e Buckminster-Fuller. Revista de Filosofia e Educação, Campinas, v. 6, n. 3, p. 235-259, out. 2014.

GALLO, Silvio. Transversalidade e educação: pensando uma educação não-disciplinar. In: Alves, N. (Org.). O sentido da escola. Rio de Janeiro: DP\&A, 2000.

GESSER, Veronica; RANGHETTI, Diva Spezia. O Currículo no Ensino Superior: Princípios epistemológicos para um Design Contemporâneo. Revista e-curriculum. São Paulo, v. 7, n. 2, ago. 2011. Disponível em: <https://revistas.pucsp.br/index.php/curriculum/article/viewFile/6775/4902>. Acesso em: 14 mai. 2017.

LEFFA, Vilson J. Transdisciplinaridade no ensino de língua: a perspectiva das teorias da complexidade. Revista Brasileira de Linguística Aplicada, Belo Horizonte, v. 6, n. 1, p. 27-49, 2006.

MACHADO, Lucília Regina de Souza. O profissional tecnólogo e sua formação. Revista da RET - Rede de Estudos do Trabalho, v. 2, n. 3, p. 1-28, nov. 2008.

MACHADO, Nilson José. Educação: projetos e valores. São Paulo: Escrituras Editora, 2006.

MANFREDI, Silvia Maria. Educação profissional no Brasil. São Paulo: Cortez, 2003.

MARQUES, Davina; MARQUES, Ivânia; SARRAIPA, Ludmila Alexandra dos Santos. Por uma perspectiva transversal: conhecendo e produzindo o mundo em imagens. Educação Temática Digital - ETD, Campinas v. 11, n. 2, p. 226-254, jan./jun. 2010.

MORIN, Edgar. Articular os saberes. In: Alves, N. (Org.). O sentido da escola. Rio de Janeiro: DP\&A, 2000. 
. A cabeça bem-feita: repensar a reforma, reformar o pensamento. Rio de Janeiro: Bertrand Brasil, 2003.

SCACHETTI, Rodolfo Eduardo. "Saber-fazer: da necessidade contemporânea de reunificação das práticas e dos conhecimentos técnicos, sociais, estéticos e políticos." In: ALMEIDA, Ivanete Bellucci Pires; BATISTA, Sueli Soares dos Santos (Org.). Educação Tecnológica: reflexões, teorias e práticas. São Paulo: Paco Editorial, 2012.

SILVA, Luciana Maria Fernandes; RUFINO, Luiz Gustavo Bonatto; DARIDO, Suraya Cristina. Capoeira e temas transversais: avaliação de um blog didático para as aulas de educação física. Educação Temática Digital - ETD, Campinas, v. 15, n. 1, p. 87-106, jan./abr. 2013.

THIESEN, Juarez da Silva. A interdisciplinaridade como um movimento articulador no processo ensino-aprendizagem. Revista Brasileira de Educação, Rio de Janeiro, v. 13, n. 39, p. 545-554, set./dez. 2008.

VILELA, Fernando. Lampião e Lancelot. São Paulo: Cosac Naify, 2006.

ZANONA, Roberta. Educar por competências na formação profissional. São Paulo: Centro Paula Souza, 2015.

\section{EMERSON FREIRE}

Doutor em Sociologia pela Universidade Estadual de Campinas e em Filosofia pela Université de Paris 1 - Panthéon Sorbonne. Professor no Mestrado em Educação Profissional do Centro Estadual de Educação Tecnológica Paula Souza (CEETEPS). E-mail: freire.emerson@uol.com.br.

\section{Rosalia Maria Netto Prados}

Doutora em Semiótica e Linguística Geral pela Universidade de São Paulo. Educação Profissional do Centro Estadual de Educação Tecnológica Paula Souza (CEETEPS). E-mail: rosalia.prados@cps.sp.gov.br.

\section{THAIS LARA BRAGA CILLI}

Mestre em Gestão e Desenvolvimento da Educação Profissional e Tecnológica pelo Centro Paula Souza (CEETEPS). Professora na FATEC Carapicuíba. E-mail: thais.cilli@cps.sp.gov.br.

Submetido em: 19-11-2018

Aceito em: 11-6-2019 